Original Research Paper

\title{
PSHA Study Using EZ-Frisk Software Case Study Baychebaq Dam Site
}

\author{
Hadi Jarahi \\ Department of Geosciences, North Tehran Branch, Islamic Azad University (IAU), Tehran, Iran
}

Article history

Received: 06-06-2017

Revised: 08-06-2017

Accepted: 10-11-2017

Email: hadijarahi@gmail.com

\begin{abstract}
Awareness of seismicity, is the earliest requirement in seismic design of Dam constructions. This article is devoted to study on Seismotectonic and seismicity and also seismic risk analysis of the Baychebaq reservoir dam. These studies involve detecting seismic sources and assessing seismicity parameters. According to the studies, Peak Ground Acceleration (PGA) is 0.1 gal. This PHA may be related to there activation process of Takhte Soleiman which can produce an event around $6.8 \mathrm{Ms}$ in the distance of $20 \mathrm{~km}$ from Baychebaq dam. According to the changes of Uniform Hazard Spectrum (UHS), Spectral acceleration parameter increases from period of $0(0.03 \mathrm{gal})$ to a period of $0.175(0.1 \mathrm{gal})$ and then reduced slightly. Based on the results, the controlling earthquake has a magnitude of 6.1 and $6.5 \mathrm{Mw}$ at a period of 0 for return periods of 475 and 2475 years.
\end{abstract}

Keywords: Baychebaq Reservoir Dam, Seismotectonic, Controlling Earthquake, Uniform Hazard Spectrum

\section{Introduction}

A level of strong ground motion can be taken to account as one of the most effective factors on the feasibility study and economic development of various structures. That's why the seismicity analyses of project developments have always been emphasized on important structures (i.e. dams, organizations and government agencies). Baychebaq reservoir dam is located at 47.23 latitude and 36.88 longitudes (decimal degrees). The site located in northwest of Iran, Zanjan province, $40 \mathrm{~km}$ northeast of Mahneshan city. The main aim of this Dam is to controlling the floodwater of the Qalechay River, (one of the leaves of Ghezelozan River). The dam is concrete type and its height is $120 \mathrm{~m}$. Dam capacity is 75-millioncube-meters. Location of the dam in comparison of the other dams in the province is significantly shown in Fig. 1.

\section{Methodology}

Probabilistic Seismic Hazard Analysis (PSHA) is a four-step operation (Reiter, 1990). The first is to identify and determine the seismic sources. The second is accountable for introducing seismicity parameters, including $\lambda, \beta$ and $\mathrm{M}_{\max }$ for each source. Selecting attenuation equations is the next. Finally, at the fourth step, uncertainty of location and magnitude related to the earthquake as well as earth movement parameter has been combined with each other and the parameters of earth movement have been estimated for the event. UHS is the response spectra which have a same evidences probability on its whole range at various periods. UHS method is prepared and designed like producing PGA (Peak Ground Acceleration) maps by probabilistic methods. The number of $m$ attenuation relationships is applied to spectra parameters at $\mathrm{m}$ periods or frequencies in UHS analysis, instead of one attenuation equations for the PGA. In another word, one spectra attenuation equations are applied for calculating each spectra parameter for each probability for desired period (i.e., $0.2,0.3$, or $0.5 \mathrm{sec}$ ) in terms of magnitude, distance and soil conditions (Baker and Cornell, 2006a; Douglas, 2011). Finally, instead of just one PGA map, m spectra iso-acceleration maps are available for desired period. Determining the probable level (50 in 50, 10 in 50, 2\% in 50 years and ...), m spectra parameters are extracted for $\mathrm{m}$ periods. Consequently, they are utilized for UHS preparation. The high number of calculations and their complexity are the main restrictions of this method (Baker and Cornell, 2006b; Douglas, 2011). Seismic hazard separation is a suitable tool for determining the magnitude and average distance; also, it can be applied to identify the major source of each seismic activity in various points. This method helps the researchers to determine distance, azimuth and magnitude of seismic sources (simultaneously with their magnitude and average distance). These historical and instrumental 
events can be applied for dynamic analyzing and seismic retrofitting (USNRC, 1997).

\section{Tectonic Setting}

Active faults have been studied based on satellite image processing and Seismotectonic map of Iran (Berberian, 1976). Considering the process, Takhte Soleiman fault, a reverse fault which has a dip toward east and $20 \mathrm{~km}$ from the Dam, is the most active structure in the region which can produce the greatest acceleration at the site.

The seismic potential of faults, existed in the area, have been calculated and, finally weighted based on experimental equations between rupture length and earthquake magnitude (Ambraseys and Melville, 1982; Zare, 1995; Wells and Coppersmith, 1994a; Nowroozi, 1985) and also logic tree (Bommer et al., 2008; Jarahi et al., 2011), (Fig. 2 and Table 1). The rupture length (surface refaulting) has been assessed around $37 \%$ of total length of the fault (Zare, 1995).

\section{Seismicity}

\section{Statistical Studies}

In order to study maximum potential seismicity of the region and also determining dispersion of events at the site, all instrumental (Engdahl et al., 2006) and historical (Ambraseys and Melville, 1982; Berberian and Arshadi, 1976) earthquakes have been collected, processed and analyzed after eliminating foreshocks and aftershocks (Powell and Duda, 1975). Moreover, in order to obtain better aspect of the seismicity potential of the region, focal depths and magnitudes of the events which happened in the region up to 50, 100, 150 and $200 \mathrm{~km}$ are presented in Fig. 1 and 3. It is concluded that the average depth of events is 7.5 to $12.5 \mathrm{~km}$ and magnitudes between 3 shows a great range among the whole events. Furthermore, it is concluded that in the further distance the frequency of events increases significantly.

\section{Activity Rate ( $\lambda$ )}

One of the most fundamental parameters in accounting ground acceleration related to a seismic component is an activity rate (Kijko, 2011; Kijko and Sellevoll, 1989; Gutenberg and Richter, 1956). Rate of seismic activity at the minimum magnitude was weighted by logical tree Fig. 2 for seismic sources. Finally, with applying appropriate weight, the significant results are obtained and presented in Fig. 4. Table 2 presents specifications of seismic sources in order to apply for software's analysis, which is calculated based on previous calculation and parameters of ruptures (Wells and Coppersmith, 1994b).

\section{Peak Horizontal Acceleration (PHA)}

In this article, a probabilistic method has been used to calculate ground acceleration for different return periods. Hence, considering seismic coefficients of each source and calculating the function of magnitude probability density and applying the use of probability theory and finally performing logical tree Fig. 2, utilized attenuation relations have been weighted and curves of seismic hazard were obtained at the site. Table 3 and Fig. 6 present the results of this analysis.

Table 1: Seismic sources in the study region

\begin{tabular}{lllll}
\hline Seismic source & Mechanism & Length $(\mathrm{km})$ & Distance to dam $(\mathrm{km})$ & $\mathrm{M}_{\max }\left(\mathrm{M}_{\mathrm{W}}\right)$ \\
\hline Takhte soleiman & Reverse & 64 & 20 & 6.8 \\
Qozlu strike & Slip & 65 & 40 & 6.8 \\
Qezelkabir & Reverse & 55 & 43 & 6.7 \\
Sangvar & Strike slip & 70 & 54 & 6.8 \\
Zanjan & Strike slip & 83 & 55 & 6.9 \\
N-Tabriz & Strike slip & 140 & 60 & 7.7 \\
Bozqush & Reverse & 92 & 73 & 7.0 \\
Khorkhoreh & Strike slip & 86 & 93 & 7.0 \\
Masuleh & Reverse & 90 & 112 & 7.0 \\
\hline
\end{tabular}

Table 2: Seismic specification applied in analysis

\begin{tabular}{|c|c|c|c|c|}
\hline \multirow[b]{2}{*}{ Seismic sources } & \multicolumn{4}{|c|}{ Seismicity parameters } \\
\hline & Activity rate $(\lambda)$ & $\mathrm{M}_{\min }$ & $\mathrm{M}_{\max }$ & Beta \\
\hline $\begin{array}{l}\text { Takhte soleiman } \\
\text {. }\end{array}$ & $1 \mathrm{E}-01$ & 4.3 & 6.8 & 2.10 \\
\hline Qozlu & $8 \mathrm{E}-02$ & 4.3 & 6.8 & 2.12 \\
\hline Qezelkabir & $8 \mathrm{E}-02$ & 4.3 & 6.7 & 2.05 \\
\hline Sangvar & $8 \mathrm{E}-02$ & 4.3 & 6.8 & 1.99 \\
\hline Zanjan & $8 \mathrm{E}-02$ & 4.3 & 6.9 & 2.00 \\
\hline N-Tabriz & $2 \mathrm{E}-02$ & 4.3 & 7.7 & 2.40 \\
\hline Bozqush & $8 \mathrm{E}-02$ & 4.3 & 7.0 & 2.10 \\
\hline Khorkhoreh & $6 \mathrm{E}-02$ & 4.3 & 7.0 & 2.15 \\
\hline Masuleh & 7E-02 & 4.3 & 7.0 & 2.00 \\
\hline
\end{tabular}




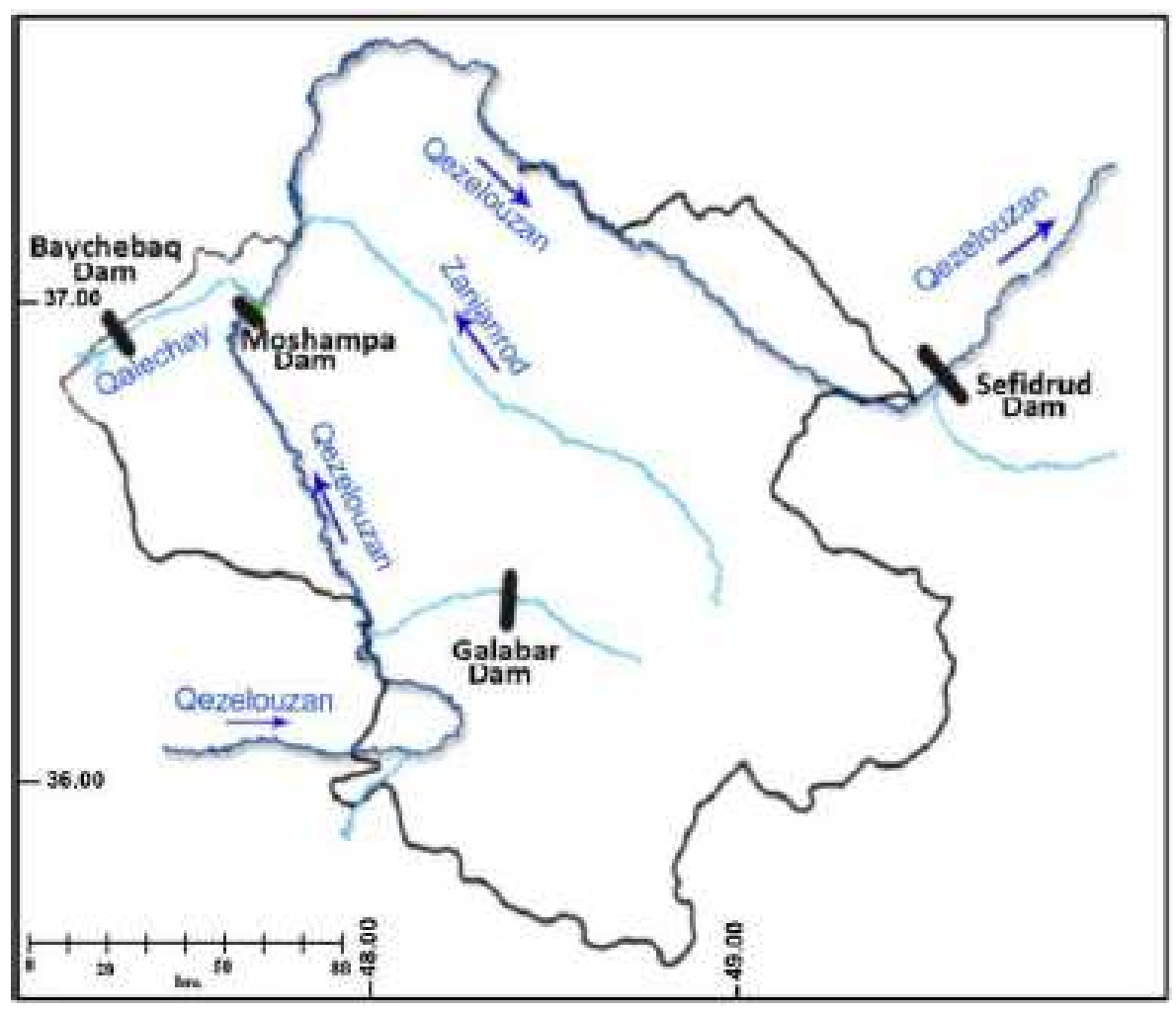

Fig. 1: Location of Baychebaq Dam across the Qezelozan River, Zanjan province

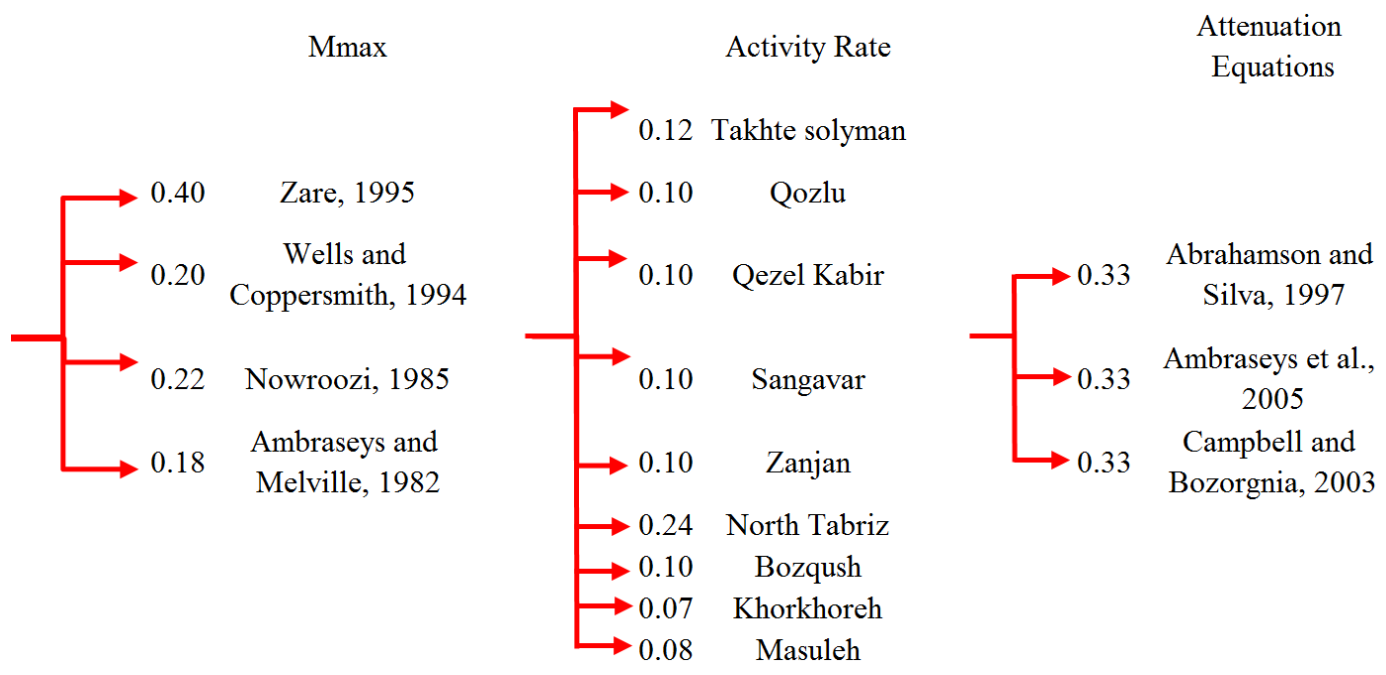

Fig. 2: The logical tree for numerical weighting (Bommer et al., 2008; Jarahi et al., 2011)

Table 3: Value of PHA and Annual Frequency of Exceedance (AFE) at the site

\begin{tabular}{lll}
\hline PHA $(\mathrm{g})$ & AFE & Return period (year) \\
\hline $6 \mathrm{E}-02$ & $2 \mathrm{E}-02$ & 50 \\
$1 \mathrm{E}-01$ & $1 \mathrm{E}-02$ & 100 \\
$1 \mathrm{E}-01$ & $7 \mathrm{E}-03$ & 145 \\
$3 \mathrm{E}-01$ & $2 \mathrm{E}-03$ & 475 \\
$4 \mathrm{E}-01$ & $1 \mathrm{E}-03$ & 975 \\
$6 \mathrm{E}-01$ & $4 \mathrm{E}-04$ & 2475 \\
$8 \mathrm{E}-01$ & $4 \mathrm{E}-04$ & 4975 \\
\hline
\end{tabular}


Table 4: Controlling earthquake in terms of distance for 475 and 2475 return periods

\section{Return Periods (year)}

\begin{tabular}{llll} 
Period (second) & Distance $(\mathrm{km})$ & 475 & 2475 \\
\hline PGA & 10.5 & 6.1 & 6.5 \\
0.2 & 11.6 & 6.1 & 6.5 \\
0.5 & 17.2 & 6.5 & 6.5 \\
2.0 & 30 & 6.8 & 6.9 \\
4.0 & 32.4 & 7.0 & 7.0 \\
\hline
\end{tabular}

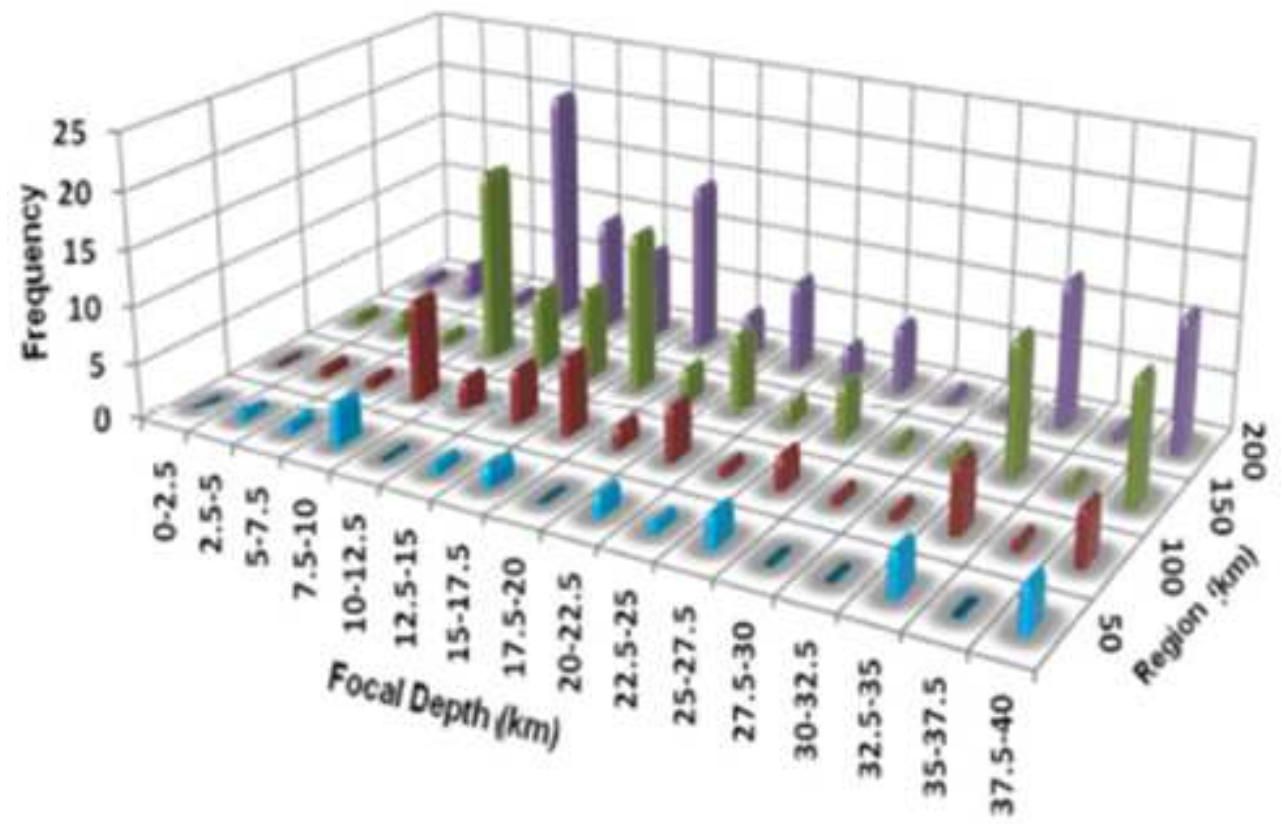

(A)

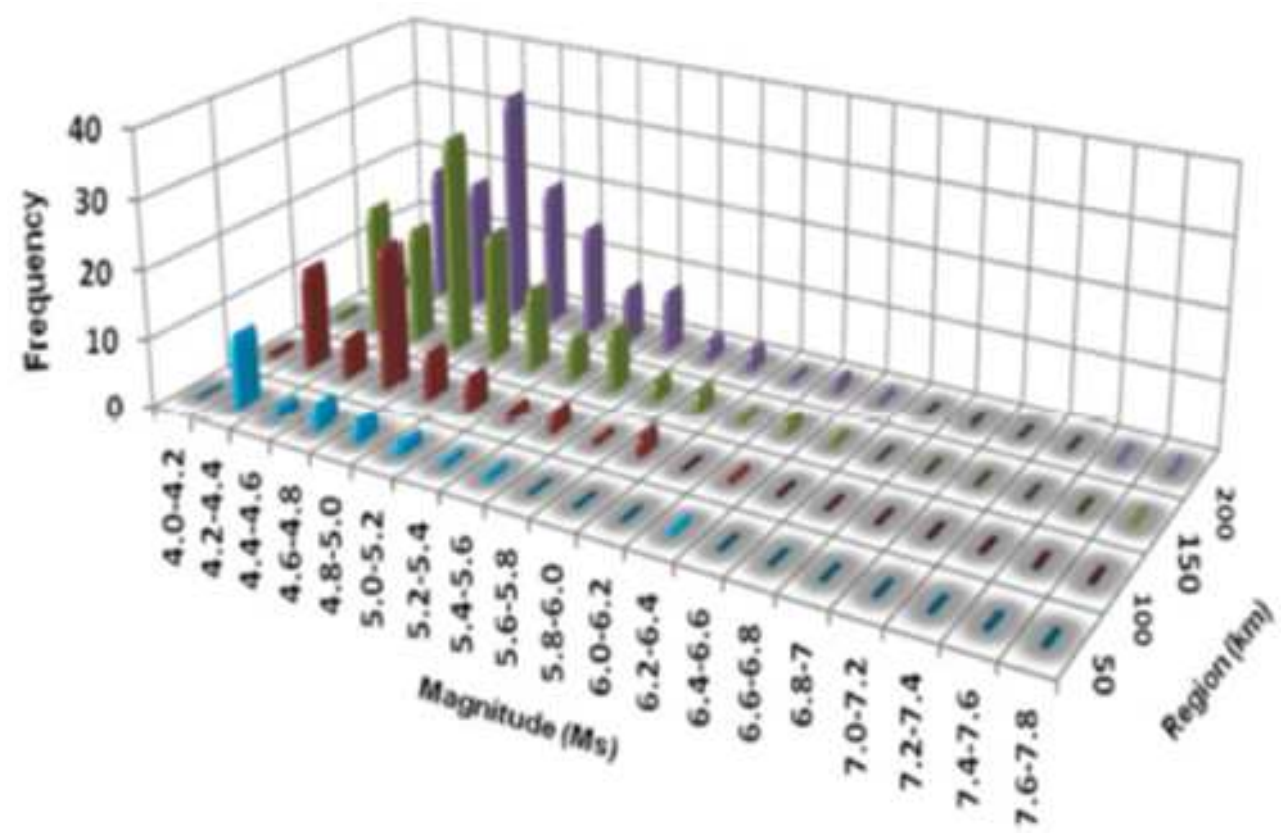

(B)

Fig. 3: (A) Frequency dispersion of focal depth (B) magnitude of the earthquakes 


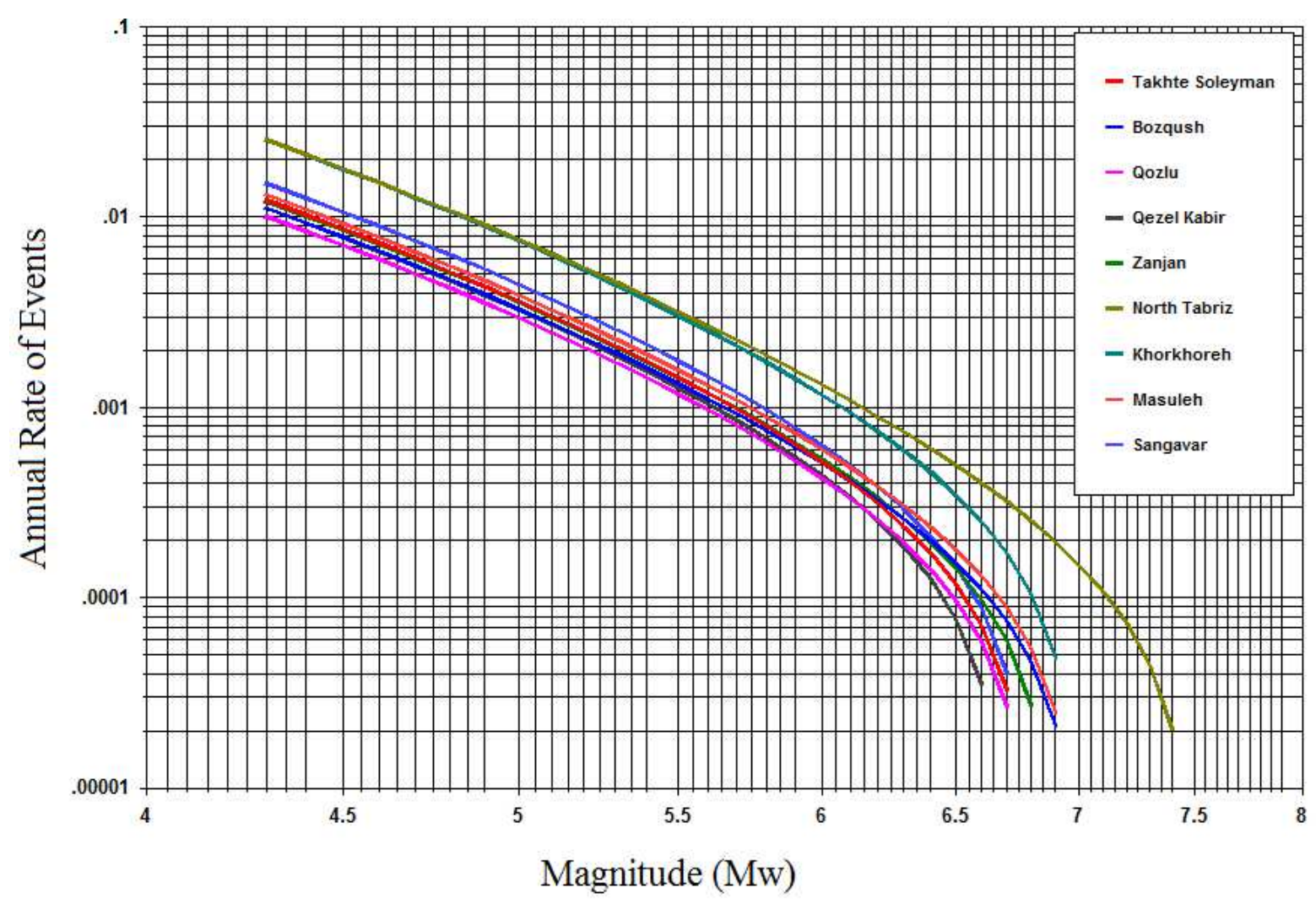

Fig. 4: Rate of seismic activity for seismic sources

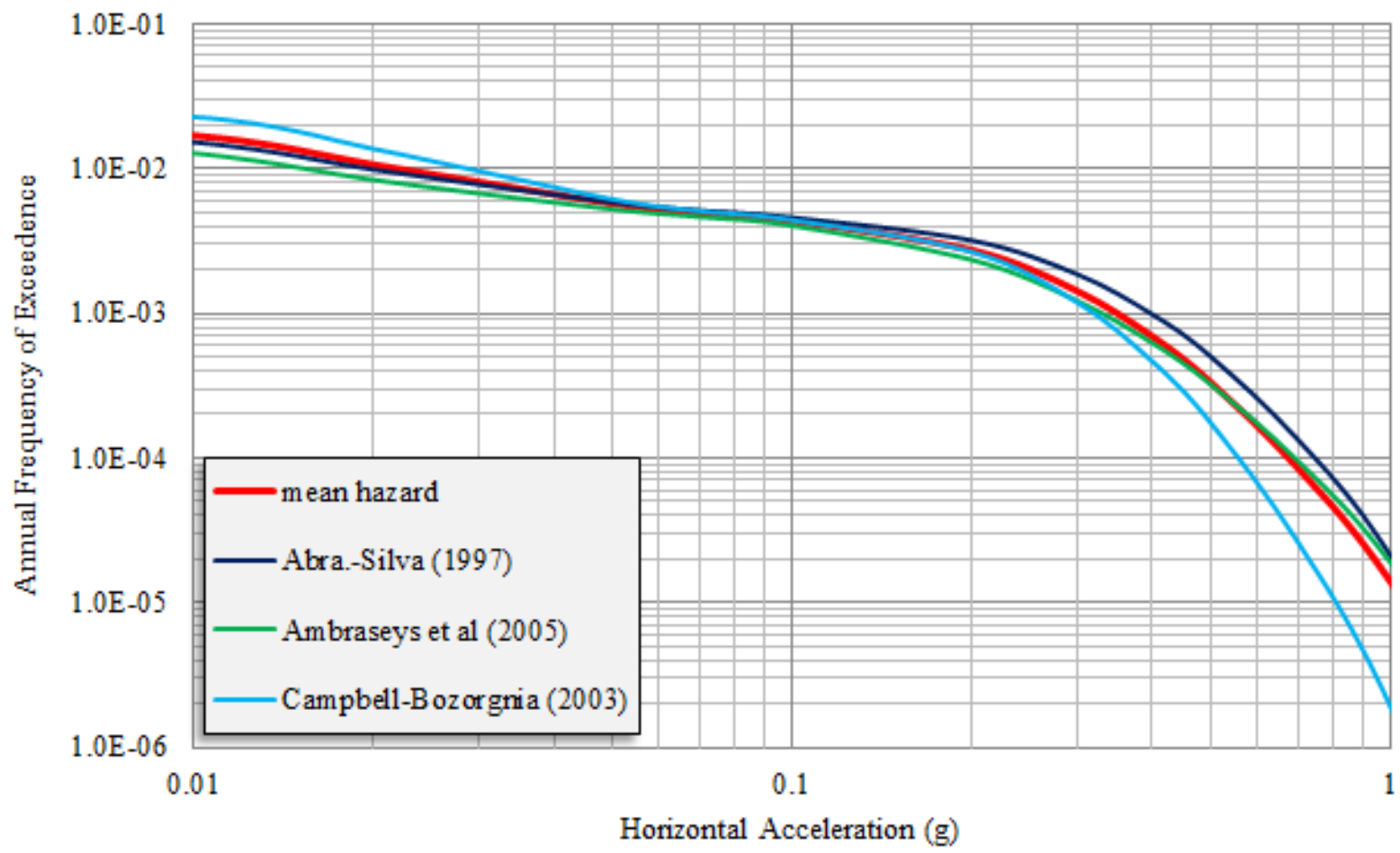

Fig. 5: The hazard curve, based on the increased 


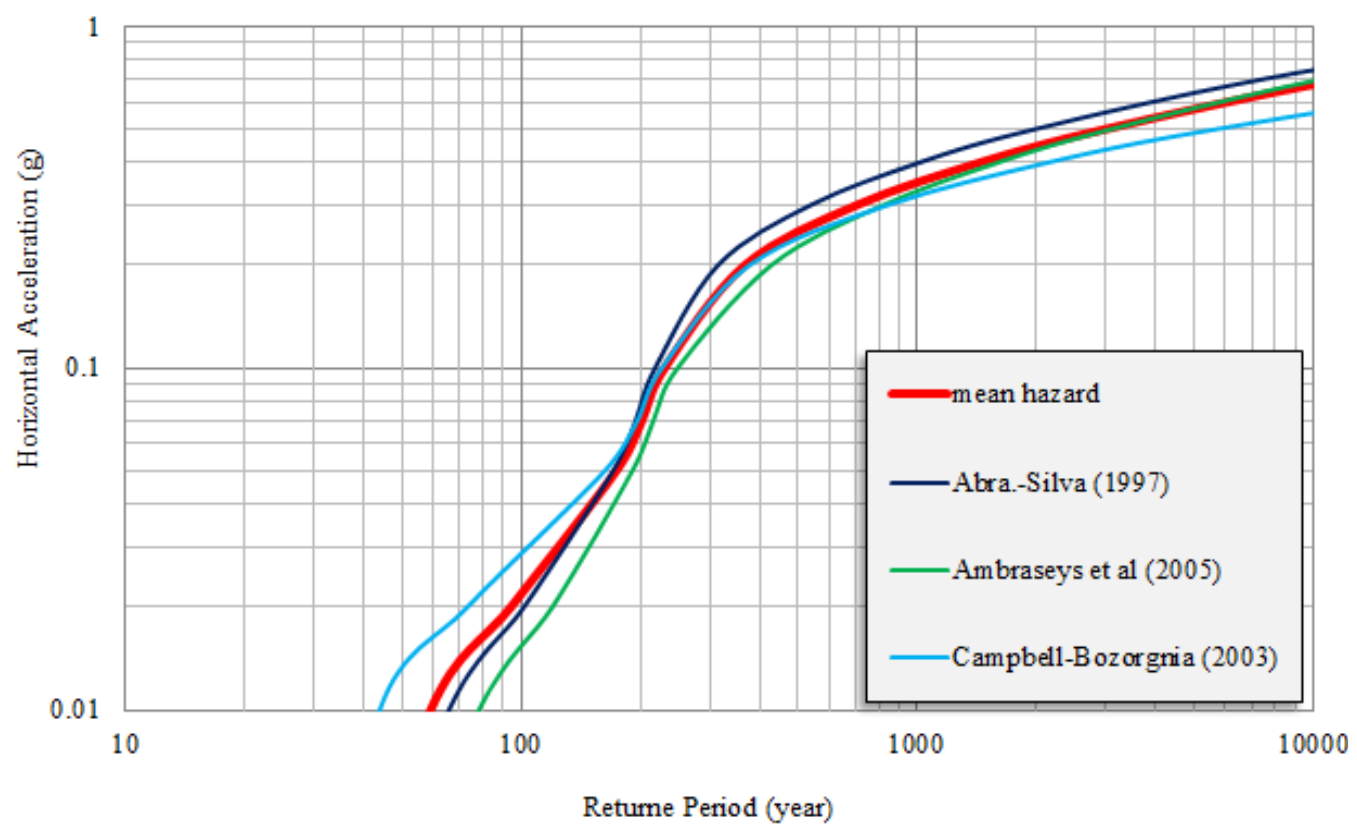

Fig. 6: The horizontal acceleration curve, based on a return period

Uniform Hazard Spectra

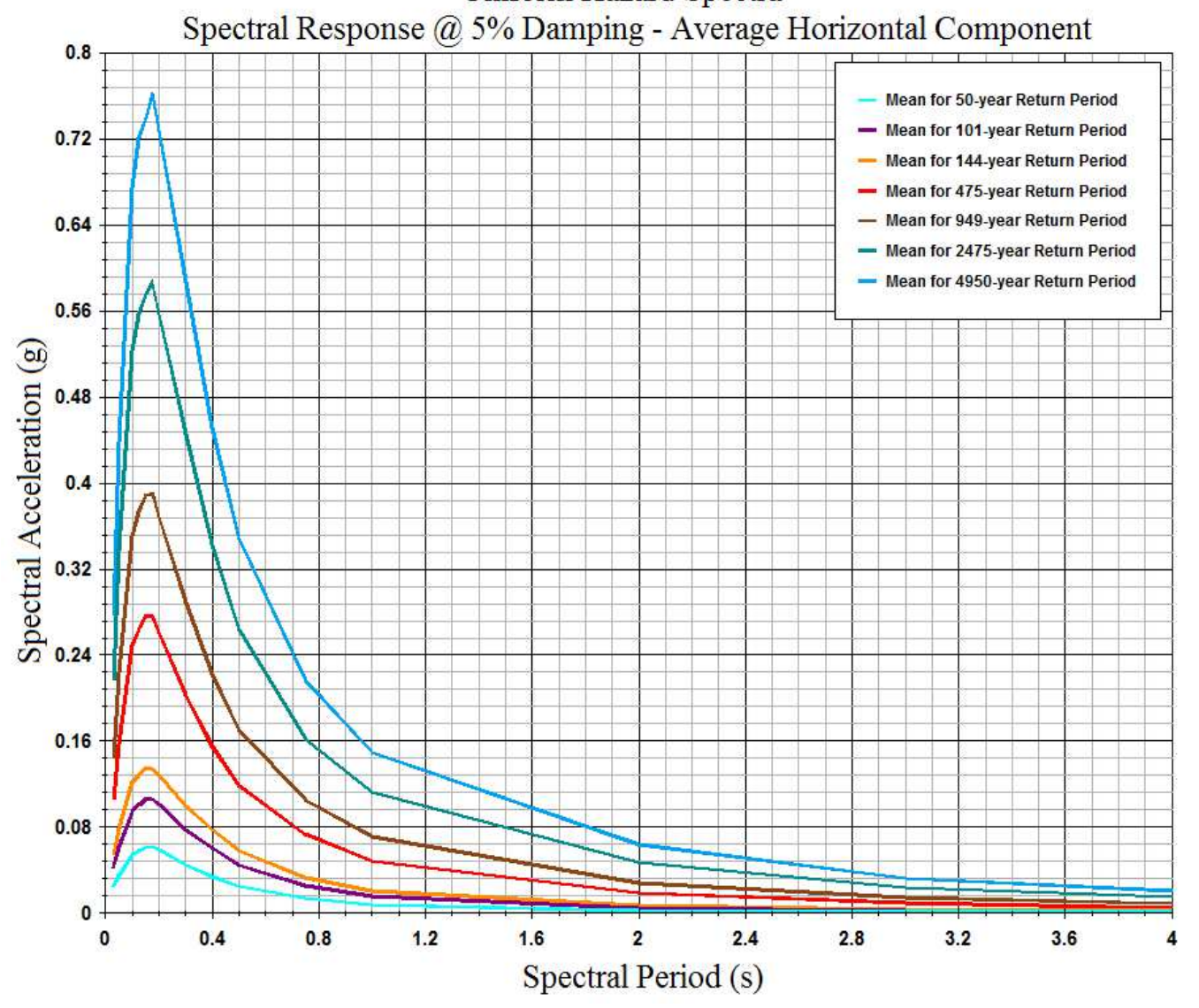

Fig. 7: The horizontal UHS, calculated by PSHA method 


\section{Uniform Hazard Spectra (UHS)}

Calculating spectral acceleration (Jarahi, 2011; Jarahi et al., 2015; Jarahi et al., 2016; Jarahi, 2016; Haerifard et al., 2018; Pourmohamad, 2006; Baker and Cornell, 2006a) is one of the most important steps in seismic designing for infrastructures like concrete dams. UHS is calculated for a period of 0 to $4 \mathrm{sec}$ by probabilistic method with the unified weight (Bommer et al., 2008) to each spectral attenuation equations (Abrahamson and Silva, 1997; Campbell and Bozorgnia, 2003; Ambraseys et al., 2005) by using EZ-Frisk software Fig. 7. Based on the analysis, Spectral acceleration increased during a period of 0 to $0.175 \mathrm{sec}$ and then it reduced dramatically.

\section{Seismic Hazard Deaggregation (SHD)}

In recent decades there has been a discussion with the earthquake risk analysis, raised as SHD (Harmsen and
Frankel, 2001; Harmsen et al., 1999; Bazzurro and Cornell, 1999). Determining the relative contribution of the seismic hazard in terms of magnitude and distance is called SHD. The participation rate of seismic sources on the acceleration of the event is assessed by this parameter (for various distances and magnitudes) in order to identify the most effective source which significantly caused the greatest acceleration in the region. In this method, the seismic risk is presented by one or more major earthquakes with Magnitude (M) and distance (R) and Earthquake parameters are chosen for engineering purposes by using this pair of $M$ and R. Figures of separated seismic hazard curves are usually presented as vertical columns which each height is proportional to the contribution of each source of seismic hazard and the horizontal axes are distance and magnitude of the earthquake as shown in Fig. 5.
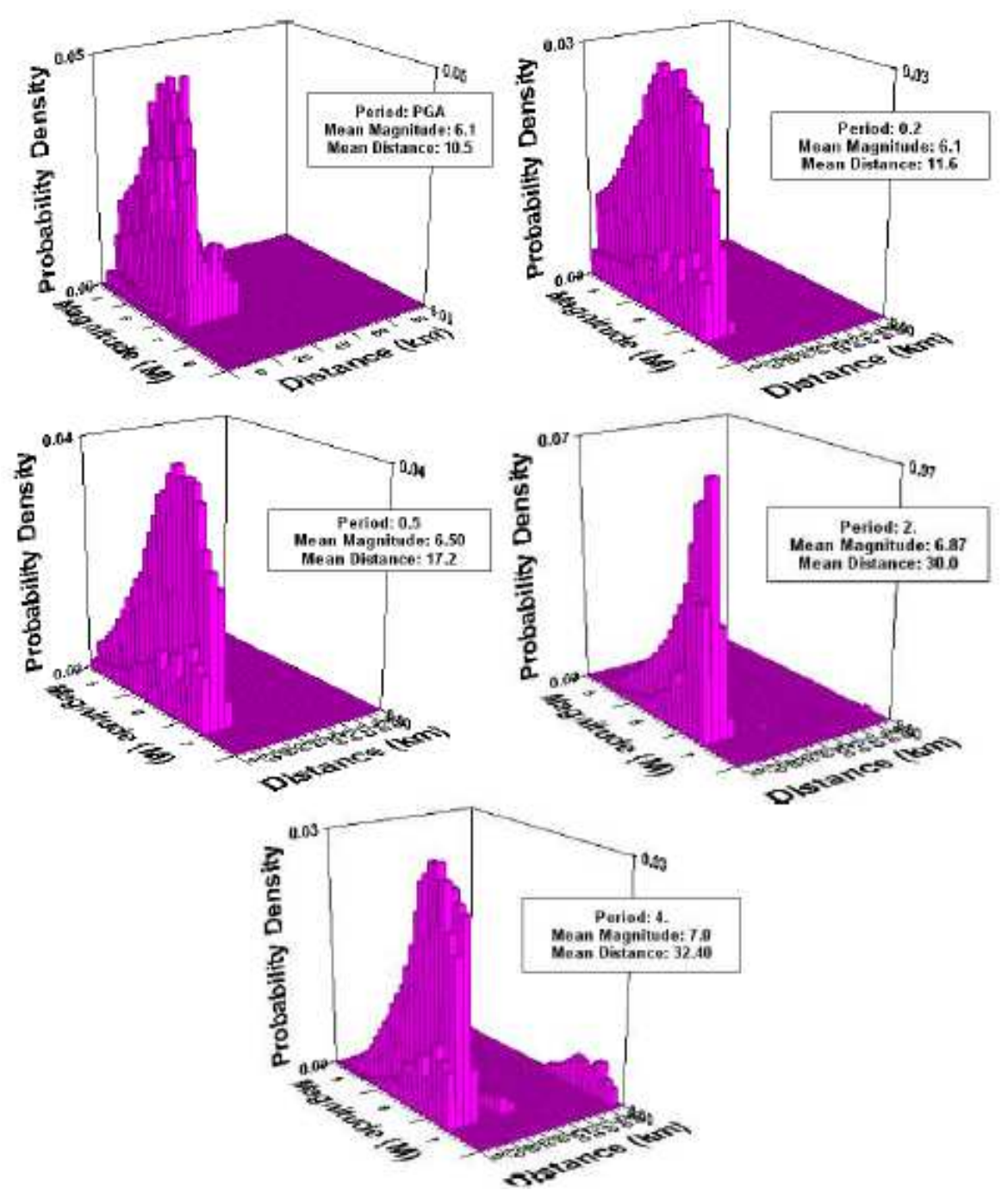

Fig. 8: Seismic hazard deaggregation (Return period of 475 years) for the particular PGA period of $0.2,0.5,2$ and 4 sec 


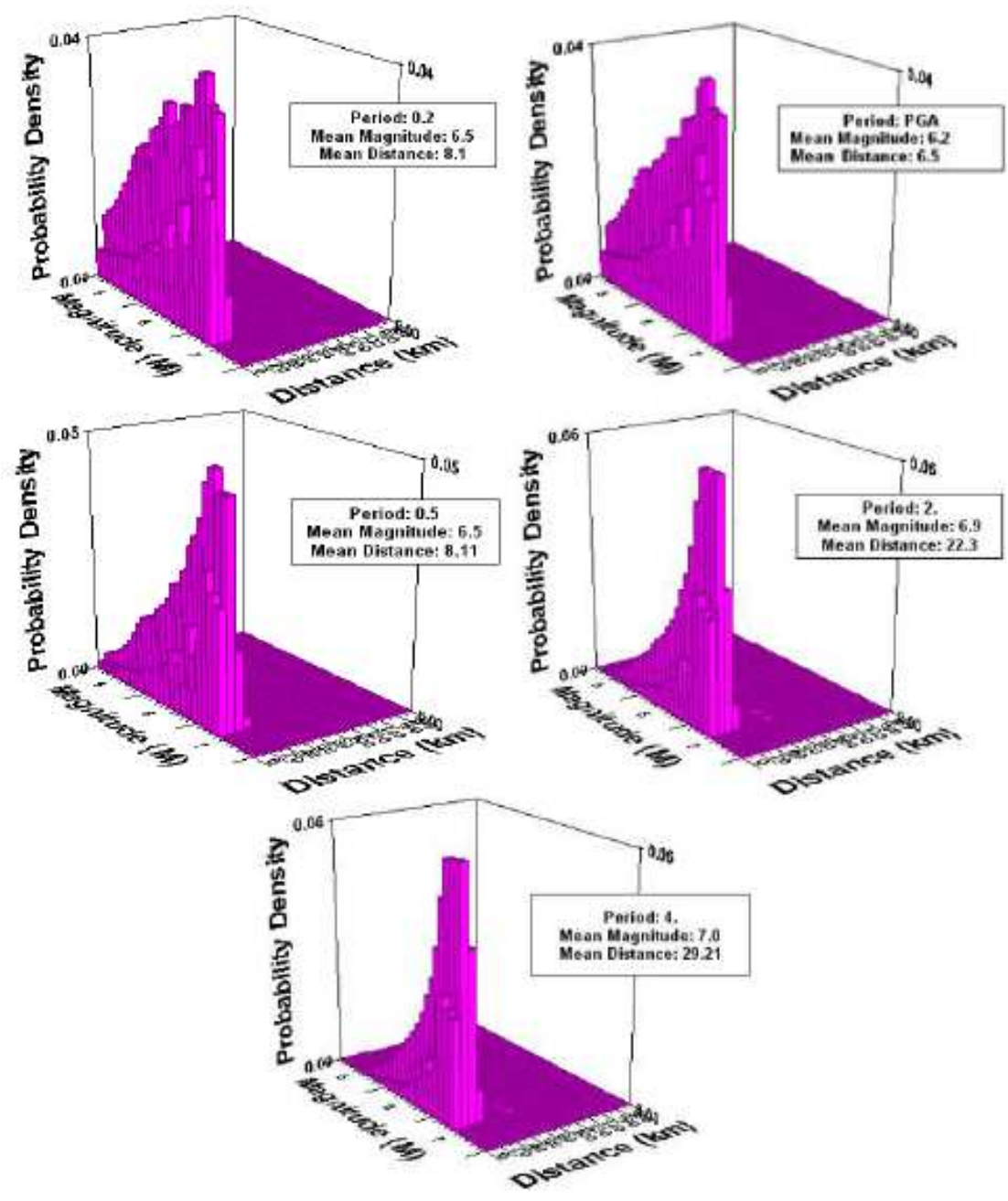

Fig. 9: Seismic hazard deaggregation (Return period of 2475 years) for the particular PGA period of 0.2, 0.5, 2 and $4 \mathrm{sec}$

In fact, the separation of PSHA stands against assessment of earthquake risk by a probabilistic method which the contributions of different sources add together in order to calculate the seismic hazard. Hence, selecting these parameters is a logical selection for simulating earthquakes. Controlling magnitude is a midpoint of a range of earthquake magnitudes that may control the design (Jarahi, 2011; Jarahi et al., 2016; Jarahi, 2016). Considering SHD, the controlling earthquakes is evaluated for return periods of 475 and 2475years with the PGA and periods of 0.2, 0.5, 2 and $4 \mathrm{sec}$ (Table 4 and Fig. 8 and 9).

\section{Conclusion}

In this paper the PHA is calculated about $0.1 \mathrm{~g}$ at the period of $0 \mathrm{sec}$ for a return period of 475 years (period of Damlife). This PHA may be related to the reactivation process of Takhte Soleiman fault which can produce an event around $6.8 \mathrm{Ms}$ in the distance of $20 \mathrm{~km}$ from
Baychebaq Dam. According to the changes of UHS, Spectral acceleration parameter increases from the period of $0(0.03 \mathrm{gal})$ to a period of $0.175(0.1 \mathrm{gal})$ and then reduced slightly. In addition, the process of SHD has been obtained to determine the controlling earthquake for PGA and periods of 0.2, 0.5, 2 and $4 \mathrm{sec}$. According to the process, the controlling earthquakes have a magnitude of 6.1 and $6.5 \mathrm{Mw}$ at a period of $0 \mathrm{sec}$ for return periods of 475 and 2475 years. Both magnitude is located $10.5 \mathrm{~km}$ far from the dam.

\section{Acknowledgements}

The author expresses his appreciation of the Mahnaz Aghababaei to his valuable helps in this research.

\section{Ethics}

This article is original and contains unpublished materials. The corresponding author confirms that all of 
the other authors have read and approved the manuscript and there are no ethical issues involved.

\section{Data and Resources}

Data retrieved from the International Seismological Centre (ISC), On-line Bulletin, http://www.isc.ac.uk, Internatl. Seismol. Cent., Thatcham, United Kingdom, 2014.

\section{References}

Abrahamson, N.A. and W.J. Silva, 1997. Empirical response spectral attenuationrelations for shallow crustal earthquakes. Seismological Res. Lett., 68: 94-127.

Ambraseys, N.N. and C.P. Melville, 1982. A History of Persian Earthquakes. 1st Edn., Cambridge University Press.

Ambraseys, N.N., J. Douglas, S.K. Sarma and P.M. Smit, 2005. Equation for the estimation of strong ground motions from shallow crustal earthquakes using data from Europe and the Middle East: Horizontal peak ground acceleration and spectral acceleration. Bulletin Earthquake Eng., 3: 1-53.

Baker, J.W. and C.A. Cornell, 2006a. Conditional mean spectrum: Tool for ground motion selection. Structural Eng., 137: 322-331.

Baker, J.W. and C.A. Cornell, 2006b. Spectral shape, epsilon and record selection. Earthquake Eng. Structural Dynamics, 35: 1077-1095.

Bazzurro, P. and C.A. Cornell, 1999. Disaggregation of seismic hazard. Bulletin Seismological Society Am., 89: 501-520.

Berberian, M., 1976. Seismotectonic Map of Iran (Scale 1/2500000). G.S.I.

Berberian, M. and S. Arshadi, 1976. On the evidence of the youngest activity of the North Tabriz fault and the seismicity of Tabriz city. Report Geol. Surv. Iran, 39: 397- 418.

Bommer, J.J., M. Eeri and F. Scherbaum, 2008. The use and misuse of logic trees in probabilistic seismic hazard analysis. Earthquake Spectra, 24: 997-1009. DOI: 10.1193/1.2977755

Campbell, K.W. and Y. Bozorgnia, 2003. Updated nearsource ground motion (Attenuation) Relation for the horizontal and vertical components of peak ground acceleration and acceleration response spectra. Bulletin Seismological Society Am., 93: 314-331.

Douglas, J., 2011. Ground-motion prediction equations1964-2010. Bureau de Recherches Géologiques et Minières (BRGM), PEER 2011/102.
Engdahl, E.R., J.A. Jackson, S.C. Myers, E.A. Bergman and K. Priestly, 2006. Relocation and assessment of seismicity in the Iran region. Geophysics J. Int., 167: 761-778.

Gutenberg, B. and C.F. Richter, 1956. Earthquake magnitude, intensity, energy and acceleration. Bulletin Seismological Society Am., 46: 105-145.

Harmsen, S. and A. Frankel, 2001. Geographic deaggregation of seismic hazard in the United States. Bulletin Seismological Society Am., 91: 13-26.

Harmsen, S., D. Perkins and A. Frankel, 1999. Deaggregation of probabilistic ground motions in the central and eastern United States. Bull. Seism. Soc. Am., 89: 1-13.

Jarahi, H., 2011. Seismic hazard analysis in Behjatabad Dam Site. M.Sc. Thesis, Department of Geosciences, North Tehran Branch, Islamic Azad University,

Jarahi H., M. Pourkermani and M. Nadalian, 2011. Seismic hazard assessment in baychebaq dam site, Northwest Zanjan Province. Proceedings of the 2nd Geo-symposium, Islamic Azad University, Ashtian Branch. Persian.

Jarahi, H., M.R. Madadi, M. Nadalian and F. Bandar, 2015. Seismic hazard Zonation in terms of spectral acceleration at Tehran region base on activity and slip rates. Proceedings of the 2nd National Congress on Construction Engineering and Projects Assessment, May 28, Semnan, Iran, OxfordCert Universal Certificate: ARTC515082173.

Jarahi, H., N. Naraghiaraghi and M. Nadalian, 2016. Short Period spectral acceleration Zonation of Tehran a comparison between slip and activity rates data's. Am. J. Geosci., 6: 36-46. DOI: 10.3844/ajgsp.2016.36.46.

Jarahi, H., 2016. Ground-motion scenarios consistent with Probabilistic seismic hazard deaggregation for Karaj city (Iran). Am. J. Eng. Applied Sci., 9: 520-529. DOI: 10.3844/ajeassp.2016.520.529

Haerifard, S., H. Jarahi, M. Pourkermani and M. Almasian, 2018. Seismic hazard assessment in esfarayen-bojnurd Railway, North-East of Iran. J. Geotectonics.

Kijko, A., 2011. Introduction to Probabilistic Seismic Hazard Analysis Encyclopedia of Solid Earth Geophysics. 1st Edn., Springer, Harsh Gupta.

Kijko, A. and M.A. Sellevoll, 1989. Estimation of earthquake hazard parameters from incomplete data files. Part I. Utilization of extreme and complete catalogues with different threshold magnitudes. Bulletin Seismological Society Am., 79: 645-654. 
Nowroozi, A.A., 1985. Empirical relations between magnitudes and fault parameters for earthquakes in Iran. B.S.S.A., 75: 1327-1338.

USNRC, 1997. Identification and characterization of seismic sources and determination of safe shutdown earthquake ground motion, regulations $10 \mathrm{CFR}$ part 100 , regulatory guide 1.165 , appendix $C$, Washington, D.C., 1.165-17/1.165-23. Nuclear Regulatory Commission.

Pourmohamad, S.M., 2006. Seismic hazard Deaggregation in bam city. $\mathrm{PhD}$ Thesis, seismology and engineering earthquake and research center.

Powell, J.A. and S.J. Duda, 1975. A statistical study of earthquake occurrence. Pageoph, 113: 447-460.

Reiter, L., 1990. Earthquake Hazard Analysis: Issues and Insights. 1st Edn., Columbia University Press, New York.
Wells, D.L. and K.J. Coppersmith, 1994a. New empirical relationships among magnitude, rupture length, rupture width, rupture area and surface displacement. Bulletin Seismological Society Am., 84: 974-1002.

Wells, D.L. and K.J. Coppersmith, 1994b. New empirical relationships among magnitude, rupture length, rupture width, rupture area and surface displacement. Bulletin Seismological Society Am., 84: 974-1002.

Zare, M., 1995. Relationships for magnitude, intensity and pike horizontal acceleration base on Iranian Earthquakes. J. Seismol. Eng. Earthquake Res., 6: 12-14. 